of lime rock of a peculiarly pure composition, which have been partially dissolved underneath the thin covering of turf which overlies the quarries whence they were obtained. At one quarry near Buxton, where a large surface has been bared, the appearance of these stones has given rise to the belief that the surface so bared has been formed by the waves of the sea, and is, in fact, an old sea-beach. This ap. pearance, however, is simply due to modern waste by solution. The author in a lengthy paper pointed out the alterations of surface from the underground waste of Gypsum beds, and also from the solution of the matrix of gritstone rocks. It was suggested in discussion that some of the recent earthquakes might have been due to subsidence arising from underground waste.

\title{
CORRESPONDENCE.
}

\section{THE PHOLAS-BORING CONTROVERSY.}

It would appear from a statement lately made by Mr. Binney, F.R.S., of Manchester, that Mr. C. P. Jopling, in 1843, brought forward the existence of what he believed to be burrows of "lithophage" at a height of about 200 feet above the sea, in Furness, as a proof of a comparatively recent submergence of the land. He referred to the immense boulders on Stainton Green, on one of which I have lately found a deep curvilinear groove, in some parts polished and lithodomized. The large specimen I sent to the Geological Society was from an altitude above the sea of about 200 feet; but some of the small specimens showing a disregard of lithological composition and structure, were from a higher level, and the paper ${ }^{1}$ referred partly to instances upwards of 600 feet above the sea. After a prolonged search, I could find none on the summits, or very near to the summits of hills, and nearly all of them were in positions to which rain could not have direct access. In some specimens the holes were bored obliquely into each other, so as to give rise to the appearance of bifurcations; but, generally speaking, they were exactly of the same form with those found by Mr. Pengelly in Devonshire, and with specimens I afterwards found in Devonshire, and described in the Geological MAGAZINE, Vol. IV., July, 1867. In Vol. IV. April, 1867, p. 189, you expressed your belief that Mr. Pengelly's specimens agreed perfectly with specimens in the late Dr. S. P. Woodward's cabinet, which contained the valves of Pholas within the cavity. I should like to see the subject fully discussed in your Magazine. I hope your correspondents will perceive that the question is not whether atmospheric action is capable of producing holes in limestone (for this all will readily admit), but whether it can give rise to the precise form of hole requiring explanation. The advocates of the atmospheric theory ought to bring forward specimens of holes exactly agreeing with the alleged Pholas-borings, from

1 See Reports of the Proceedings of the Geological Society in the June number of this Magazine, p. 282. 
walls of buildings, or from quarries, where the commencement of atmospheric action can be traced.
Manchester, 31st May, 1869.
D. Madkintosh.

TEETH OF OLIMAXODUS, FROM THE COAL MEASURES.

Sir,-I again venture to trouble you with a few remarks on the rare Coal-measure fish Climaxodrs, about which, so far as I have been able to ascertain, nothing whatever is known beyond the fact of its having possessed teeth of a very peculiar form.

On page 496 of the Geologicas Magazinid (November, 1868), there appears a figure of the first specimen of Climaxodus discovered by me in the shale of Newsham Colliery, Northumberland, and at page 42 (January, 1869), reference is made to three additional specimens from the same Colliery. Since those communications appeared I have found four specimens of Climaxcodus, three of which closely resemble the figure just referred to, but one appears sufficiently destinctive in its form to justify its being erected into a new species. In size it very closely resembles that which I named Climaxodus ovatus, but in its general outline, and especially in the ridges which traverse its surface, it is remarkably unlike any specimen I have previously found or examined. I propose for it the specific name vermiformis, as descriptive of its leading peculiarity, viz. the possession of vermiform ridges across its surface. Climaxodus vermiformis, is from the Low Main Coal Shale, Newsham Colliery, Northumberland.

General character: Tooth longer than wide, gradually narrowing towards the posterior extremity, the crown crossed by vermiform, irregularly bent, transverse ridges at right angles to its length; the surface somewhat rough and granular.

Climaxodus vermiformis, sp. nov. The specimen is nearly perfect, a fragment of the posterior extremity being absent; the length of the specimen is six-eighths of an inch, the width at the broadest part is also six-eighths, and the narrow posterior end is four-eighths of an inch wide; the crown is crossed by three very irregular vermiform ridges, the second ridge being excessively bent, at one part of its course it approaches the first ridge within one-sixteenth of an inch, and at another part it is four-sixteenths of an inch from it; the third ridge is imperfect, but the portion that remains indicates that it also crossed the crown of the tooth in a tortuous manner, the crests of the ridges on the crown of the tonth are nearly on the same level, and the spaces between each ridge are deeply concave; the surface of the bone forming the tooth, when seen by means of a microscope, presents a shimmering lustre, although the tooth, when examined by the naked eye, appears perfectly black. The tooth is attached to a thin plate of bone, and the curve of the plate supporting the tooth is sigmoidal and resembles that of $\mathrm{Cli}$ maxodus ovatus, a specimen of which may seen in the British Museum by anyone who is desirous of an acquaintance with the teeth of this obscure Carboniferous fish.

T. P. BARKAS.

NewCastle-on-Tyne, June 11th, 1869. 